Ergot may be administered in some form. If this fails, recourse should be had, after certainly not more than a quarter of an hour's trial of it, to the underrunning as above described.

The cause of this kind of hæmorrhage is at present unknown. It has been put down to septicemia, syphilis, hrmophilia, and other causes; but various observers have failed to find any constant histological evidence of the first two. Grandidier collected 220 cases, of which 84 had icterus neonatorum and 61 had petechire in various places. Mechanical and developmental defects in the heart and organs of circulation have been found associated with it in some cases, as have also certain diseases of the liver. In some cases of jaundice the child may be dying from some other cause than the hæmorrhage, which is only a symptom of the graver disease.

In reference to the relation of hremophilia to this accident, two cases which occurred in the General Lying-in Hospital suggest a hereditary tendency of some sort. In one that of a female child, there was a history of a maternal uncle, who was said to be subject to hæmorrhages and painless swellings of the joints, and the child had at the same time as the bleeding from the umbilicus, which occurred on the ninth day (stump separated on the seventh), several ecchymoses ranging from the size of a five-shilling piece to that of a shilling. These were doubtless the result of slight pressure on the spots where they occurred, which were the right elbow, both axillæ, the left wrist, the dorsum of the right hand, and the suboccipital region. There were no scattered purpuric spots, and no jaundice. The mother had not lost more than the usual quantity at her confinement. In another case bleeding oceurred on the ninth day (stump separated on the seventh) in a female child, who on the eighth day vomited a little blood, and had a "show"that is, passed blood per vaginam-for two days, the eighth and ninth. The mother had a phlebolith in her left radial vein, the only one remaining of four which had appeared in a line in the forearm some years before, with no definite syniptoms as far as she remembered. On the ninth day she developed phlebitis in the left internal saphenous vein, which spread down to the level of the knee and extended into the femoral vein, with the usual symptoms. She lost more than ordinary at her labour, for no obstetrical reason--viz, fifteen ounces before, six ounces with, and four ounces after the placenta. The baby was slightly hoarse on the fourth day, but no other signs of syphilis were discovered in it, and none in the mother. These were the only two cases occurring in the six months; both were females, and in both there seemed some hereditary tendency.

There is some ground for assuming a close connexion between bleeding from the umbilicus, from the vagina (which is by no means rare), vomiting of blood, and transitory infantile jaundice on the one hand, and the changes in the consistence and composition of the blood described as occurring soon after birth by Colinstein and Zuntz ${ }^{1}$ on the other. The whole subject has still to be worked out. The most complete account of these matters, as far as our present knowledge goes, will be found in Baginsky's Lehrb. d. Kinderkrunkh. (2nd edition, translated), and in Gerhardt's Kinderkrankh. (vol. ii.) Fischl has a paper on the subject in the first volume of the Archiv für Kinderheilh., and another in the eighth volume. There are many other writers on the subject, among whom Grandidier is the most important.

1 Pfliger's Archiv, vol, xxxiv., p. 173.

General Hospital, Birmingham.-The annual report-the 109 th-for the last year shows that the total of in- and out-patients treated was 45,137 . The total expenditure for 1888 was $£ 15,198$. The year began with a deficiency of $f 6847$, and closed with an increased adverse balance of $£ 7942$. The committee acknowledge the generous gift of Mr. S. C. Holder, consisting of two new annexes of four stories each to two of the wings of the lospital, which had been erected and equipped at his sole expense. The third annual report of the committee of the Jaffary Suburban Hospital states that the hospital was now complete; the donations had reached a total of $\{38,866$. From the medical statement it appeared that during the year 3614 patients had been treated. The report was adopted.

\section{Clinical allotes:}

\section{MEDICAL, SURGICAL, OBSTETRICAL, AND} THERAPEUTICAL.

CASE OF

FEMORAL HERNIA IN WHICH A PERFORATED

VERMIFORM APPENDIX WAS FOUND IN

THE SAC; EXCISION OF SAC AND

APPENDIX; CURE

By Timomas ANNANDALE, F.R.C.S.

REGIUS PROIESSOR OF CLINICAL SURGERY, UNIVERSITY OF HDINBURGIY.

ON Dec. 21st last I was asked to see, in consultation with Dr. Carrnichael of Edinburgh, Mrs. M-, aged sixty, who was suffering from an inflammatory swelling in her right groin. She gave me the following history. About twenty years ago she noticed a swelling in her right groin, which did not give her much inconvenience. Her medical attendant examined the tumour and pronounced it to be a rupture, and advised her to wear a truss. His advice was: not taken, and as the hernia caused her little trouble she did nothing for it. Her opinion is that the swelling at times disappeared altogether, but her evidence upon this point was not strong. Thirteen days before $I$ saw her the swelling increased in size, became very tender, and caused a little general fever. The usual soothing remedies were employed, but the inflammatory symptoms became acnte, and, as suppuration had taken place, I was asked to visit her. In the right groin there was a somewhat diffuse inflammatory swelling, and all the signs of diffuse suppuration. There were no signs of intestinal obstruction, but some nansea was present. Having administered chloroform, I made a free incision over the swelling, and, keeping in view the history of a hernia, I was careful to open the suppurating cavity by dissection rather than by a plunge of the knife. This cavity was not markedly circumscribed, and it contained a quantity of pus and blood, and when this had escaped a well-defined and rounded tumour, the size of a mandarin orange, was seen. An examination readily decided that this was the sac of a femoral hernia, the walls of which were much thickened from implication in the surrounding inflammatory condition. The sac was now opened, when pus and blood escaped from its cavity. The only contents of the sac in aldition to these fluids was the vermiform appendix, which was thickened and congested. The base of the appendix was firmly adherent to the inner aspect of the neck of the sac, and thoroughly plugged it. After separating the body of the sac from the surrounding parts, the neck of the sac, including the base of the appendix, was firmly ligatured with catgut, and then both sac and appendix were cut away. The stump of the sac where ligatured was now stitched in position by two or three subcutaneous catgut sutures, after the manner of a radical operation. No trouble followed the operation, and the wound was soundly healed on Jan. 19th. The portion of appendix removed measured three inclies and a half in lenoth, and connected to one side of it was a short portion of mesentery, with a considerable derelopment of fatty tissue in it. About an inch from the extremity of the appendix there was a small perforation which opened into its canal, but no concretion or foreign body was present, although it is quite possible that a small concretion may have escaped in to the suppurating sac and been overlooked.

Fainburgh.

\section{PERIPHERAL NEURITIS DUE TO THE VOMITING OF PREGNANCY.}

\section{BY D. W. WhitFieLd, M.R.C.S., L.K.Q.C.P.I.}

THE following case, illustrating one of the rare diseases which may occur as a sequel to prolonged and excessive vomiting during pregnancy, may be of interest.

Mrs. R_, aged forty, a lady of strictly temperate habits, was delivered of a fairly well-nourished female child at full time on Aug. Tth, 1888. This had been her seventh pregnancy. Her previous pregnancits had been $\mathrm{N}: 2$ 
unattended with much sickness. During this pregnancy, however, the sickness was troublesome from the first, and it increased as the pregnancy advanced, the skin assuming a most unhealthy, sallow appearance, as if the liver was not acting. She lost flesh rapidly, but was not confined to her bed until the end of the sixth month, when she had a most severe attack of vomiting, large quantities of bile being romited up. For about a fortnight hardly anything seemed to be retained, and she became so prostrated that $I$ began to think it would be necessary to induce labour. However, at the end of a fortnight she improved a little, and some water gruel and essence of meat were retained. In another week she was able to sit up a little each day, but still the vomiting never ceased entirely, and until her confinement not a day passed without severe attacks of it. All the usual remedies were tried without much effect. Bismuth seemed to do the most good. She was now able to sit up each day, and was downstairs the day before her confinement. A fortnight previously, however, she felt her legs cold, and found she was losing the use of them; she had to be assisted up and down the stairs. She had no pain-only the feeling of coldness in the legs; she tried to obtain warmth in them by sitting before the fire, but in vain. Prior to this pregnancy she was a little inclined to stoutness, and I think she lost at least $80 \mathrm{lb}$. in weight. Labour was quite natural, lasting about five hours. The romiting ceased the day after, and she began to take nourishment. She had no rise of temperature, the lochia were normal, and it was thought she was doing well. However, after the fourth day she complained of her legs feeling numb, and a few days afterwards of severe pains in them and of "pins-andneedles" in the hands, a burning sensation in the palms, and pains up the arms. She could move her legs slightly in bed, and the wrists did not drop until the twelfth day after confinement. On the thirteenth day we got her out of bed, and it was then that I saw the extensive nature of the disease. Dr. Dreschfeld saw her with me on this date, when we found she had almost lost the entire use of both arms and legs. She was unable to bear the slightest weight on her legs, and had difficulty in crossing one over the other. The patellar and other reflexes were absent; both feet were extended and the toes flexed; the hands were dropped, the wrist and fingers were flexed, and she had no power to extend them. She had difficulty in raising herself in bed, and complained of a peculiar numb feeling around the lower part of the abdomen and epigastric region. The breathing fortunately was unaffected. There was pain on pressure over the main nerve trunks in both arms and legs. The cutaneous sensibility varied in different placesincreased in some parts, diminished in others. We gave her liq. strychniæ, and employed massage, and in about a week she began to improve. The improvement has been slow but continuous, and at the present time the arms, forearms, thighs, and trunk are almost well, but the hands, legs, and feet are not. She cannot bear any weight on the feet as yet, although she can flex them and move them about more freely, and power is certainly returning gradually.

Remarks. - Of course peripheral neuritis may come on during any wasting disease, and very rarely after a confinement ; but I am not aware of any case having been described which has been due to excessive vomiting during pregnancy. The ouestion is, whether, should the symptoms show themselves during an excessively sick pregnancy, it would not be a sufficient reason for inducing premature labour. In this case the early symptoms were extreme coldness of the lower limbs from the hips downwards, with partial loss of power, followed by a feeling of numbness.

Manchester.

\section{CASE OF ABSCESS OF LIVER; OPERATION; RECOVERY.}

Bx Walter Falla, M.R.C.S., L.R.C.P., STRGEON TO THE JERSEY GENERAL HOSPITAL.

ON Nov. Plst last I was called to see L. S- - aged twenty-six, of temperate habits. He had been ill about a fortnight, and complained of great pain in the epigastrium, with occasional rigors, and a temperature of $103^{\circ}$. On examining the abdomen, $I$ found a distinet fulness, dull on percussion, over the left lobe of the liver, which was very tender on pressure. The pain was relieved by hot fomentations and opiates for a few days, but the swelliing gradually increased, the temperature varying from $102^{\circ}$ to $105^{\circ}$, while he was rapidly losing appetite and flesh. On Nov. 28 th, Dr. Bentlif kindly saw the case in consultation with me, and agreed that the diagnosis was abscess of the left lobe of the liver. The following day, after first confirming our diagnosis by making an exploratory puncture with a hypodermic syringe, we decided to aspirate, and withdrew four ounces of deep-seated pus. The relief which followed was only very temporary; the swelling in the epigastrium soon reappeared, and increased so rapidly that on Dec. 4th it was larger than ever. We decided again to operate at once. Dr. Bentlif administered chloroform, while I made a free incision, letting out about six ounces of pus. I inserted a drainage-tube, and dressed the wound with iodoform and carbolised wool ; the temperature very soon became normal, and he made a speedy recovery. The wound was dressed daily, the abscess cavity washed out with a warm and weak solution of carbolic acid, and the drainage-tube removed seven days after the operation. On Dec. 16 th the wound had quite healed, and the patient was able to get up, feeling almost quite well.

Remarks. - This case is interesting, not only as occurring in a person who has never lived in the tropics, but also on account of his youth and temperate habits, and without any apparent cause to account for it. I have seen several cases of abscess of the liver in India. With regard to treatment, my experience has been that aspirating is very rarely sufficient to effect a cure ; in the great majority of cases, it is either necessary to make a free incision or to puncture with a large trocar and cannula, so as to allow free drainage.

st. Heliers, Jersey.

\section{g a}

\section{OP}

\section{HOSPITAL PRACTICE, BRITISH AND FOREIGN.}

Nulla autem est alia pro certo noscendi via, nisi quamplurimas et morborum et dissectionum historias, tum aliorum tum proprias collectas habere, et inter se comparare.-MORGAGNI De Sed. et Caus. Hiort, lib. iv. Procemium.

\section{GUY'S HOSPITAL.}

VAGINAL LITHOTOMY IN A PATIENT SIX MONTHS AND A

HALF PREGNANT; IMMEDIATE SUTURE OF WOUND;

RECOVERY ; NORMAL DELIVERY AT FULL TIME ; REMARKS.

(Under the care of Mr. JACOBSON.)

THE operation for removal of a stone from the female bladder may be performed by cystotomy in four different ways. 1. By the direct method, a transverse incision between the urethra and the pubes, not now used. 2. Division of the urethra and neck of the bladder, either immediately or after a lateral incision. 3. Incision above the pubes. 4. Vesico-vaginal incision as practised by $\mathrm{Mr}$. Jacobson, who gives reasons for the employment of this method in his remarls on the case. ${ }^{1}$ Hugenberger has collected a series of twenty-three cases of stone in the bladder during pregnancy, from which it appears the operation for their removal has been practised at different, periods of pregnancy, but although the stone has been removed successfully, death has not unfrequently occurred. Should a calculus only be discovered during parturition, and its size or position in front of the advancing head prevent its displacement to a part where it is less likely to cause damage, it may be necessary to perform the operation of vaginal cystotomy. We have frequently drawn attention to the operation of lithotomy in the fenale in the columns of THE LANCET. ${ }^{2}$ The following account is taken from the notes of the case by Mr. J. H. Bryant.

A. L- , aged twenty-seven, was sent to the hospital by Dr. Montagu Day, of Harlow, Essex, on Dec, 7th, 1888. She had lived in that neighbourhood all her life. For about three years she had had "bladder trouble"-viz., hypogastric pain, cystitis, very frequent micturition day and night, with

See Gant, Science and Practice of Surgery, vol. ii., p. 982.

2 1838-9, vol. i., p. 58 ; 1862 , vol. ii., p. $478 ; 1863$, vol. i., p. $34 ; 1870$, vol. ii., p. 853 ; 1885 , vol. ii., p. 847 . 